\title{
TRUE TO ONESELF? BROAD AND NARROW IDEAS ON AUTHENTICITY IN THE ENHANCEMENT DEBATE
}

\begin{abstract}
Our knowledge of the human brain and the influence of pharmacological substances on human mental functioning is expanding. This creates new possibilities to enhance personality and character traits. Psychopharmacological enhancers, as well as other enhancement technologies, raise moral questions concerning the boundary between clinical therapy and enhancement, risks and safety, coercion and justice. Other moral questions include the meaning and value of identity and authenticity, the role of happiness for a good life, or the perceived threats to humanity. Identity and authenticity are central in the debate on psychopharmacological enhancers. In this paper, I first describe the concerns at issue here as extensively propounded by Carl Elliott. Next, I address David DeGrazia's theory, which holds that there are no fundamental identity-related and authenticity-related arguments against enhancement technologies. I argue, however, that DeGrazia's line of reasoning does not succeed in settling these concerns. His conception of identity does not seem able to account for the importance we attach to personal identity in cases where personal identity is changed through enhancement technology. Moreover, his conception of authenticity does not explain the reason why we find inauthentic values objectionable. A broader approach to authenticity can make sense of concerns about changes in personal identity by means of enhancement technologies.
\end{abstract}

KEY WORDS: authenticity, autonomy, cosmetic psychopharmacology, enhancement, neuroscience, personal identity

\section{INTRODUCTION}

Our knowledge of the human brain and about the influence of pharmacological substances on human mental functioning is expanding and, increasingly, this creates new possibilities for enhancing the mental functioning of humans. Some examples are brain-machine interfaces (BMI) that may allow interaction between neural tissue and electronic transducers, and technologies such as deep brain stimulation (DBS) and transcranial magnetic stimulation (TMS). Psychopharmacology has been characterized as being "on the leading edge of neurotechnology." A number of drugs are already 
used for enhancement purposes. For example, students in the USA use Ritalin while cramming for their exams. Modafinil, a promising remedy for sleep loss that improves alertness and cognitive performance, is being tested for use in the army. ${ }^{2}$ Donepezil, medically indicated for mild to moderate Alzheimer's disease, was tested in healthy pilots in a flight simulator; it improved retention of training and episodic (long-term) memory. ${ }^{3}$ Future cognition enhancers may be more effective because these drugs target the specific mechanisms that underlie memory formation.

These developments compel us to reflect on the moral questions they evoke and on the need for public policy. Some of the moral questions relate to the boundary between clinical therapy and enhancement, risks and safety, coercion and justice. Other moral questions involve the meaning and value of identity and authenticity, the role of happiness for a good life or the perceived threats to humanity. Here, I will focus on questions regarding identity and authenticity - a central issue in the debate. Proponents hold that psychopharmacological substances can help users to become who they really are and thus strengthen their identity and authenticity. Critics, however, believe that the substances will lead to inauthenticity, normalization, and socially-enforced adaptation of behavior and personality. Some even fear dehumanization in the long run. Proponents as well as critics of enhancement technologies share the moral ideal of authenticity. However, they understand authenticity differently. ${ }^{4}$

I first describe the argumentation of Carl Elliott, who raises identity-related and authenticity-related concerns about psychopharmacological enhancement technologies. Next, I consider David DeGrazia's reasoning to the effect that there are no fundamental identity-related and authenticity-related arguments against enhancement technologies. The views of Elliott and DeGrazia may be characterized as examples of the opposing views between critics and proponents of enhancement technologies. My aim is to show that DeGrazia does not succeed in settling the concerns of critics, such as Elliott, completely. DeGrazia's exposition of identity cannot account for the importance we attach to identity in cases in which personal identity is changed through enhancement technology. Moreover, his account of autonomy - which includes authenticity - cannot sufficiently cover the reason why we find some enhancement technologies problematic. Finally, I conclude that we need alternative broader interpretations of authenticity in order to debate enhancement 
technologies properly, as well as to address the question how medicine has to deal with the demand for enhancement technologies.

\section{COSMETIC PSYCHOPHARMACOLOGY: A THREAT TO AUTHENTICITY?}

The value and impact of cosmetic psychopharmacology and other enhancement technologies have been heavily debated, and Carl Elliott is one of the main contributors. Elliott is concerned with a particular sort of worry about cosmetic psychopharmacology: a certain unease with the use of psychopharmacological substances by people who suffer from existential "illnesses," who "feel disoriented and lost in the world." Elliott asks his readers whether a psychiatrist should prescribe Prozac to a man suffering from spiritual emptiness and alienation: "an accountant living in Downers Grove, Illinois who comes to himself one day and says, 'Jesus Christ, is this it? A Snapper lawn mower and a house in the suburbs?" ${ }^{96}$ Some of us may be of the opinion that the psychiatrist should abstain from prescribing Prozac in this case because existential problems, like alienation, belong to the human condition. This answer to Elliott's question may run along the lines of the report by George W. Bush's President's Council on Bioethics; according to this Council, enhancement may threaten our sense both of human dignity and of what is naturally human. ${ }^{7} \mathrm{We}$ may forget what full flourishing or true human happiness really entails. Full human flourishing comprises more than mere happy feelings and requires a connection to reality, as opposed to the unnatural or artificial improvement of mood that drugs bring about. For example, the use of memory blunters is considered to be morally problematic because it might cause a loss of empathy if we would habitually erase our negative experiences, and because it would violate the human duty to remember and oppose crimes and atrocities. According to Elliott, our concern and ambivalence with respect to the use of enhancers is rooted in our own form of life. Elliot does not focus on human beings in general but on $20^{\text {th }}$ century Westerners and their specific experiences of alienation. To be more precise, Elliott claims that our concerns stem from a framework by which we determine whether our lives have sense or meaning. Following Charles Taylor and Lionel Trilling, he calls this framework an ethic of authenticity. He sketches two important features of this framework. The first feature is the notion of life as a project, i.e., the 
idea that whether our life has meaning is self-determined and, moreover, that we see our life as "planned undertakings" which we in a significant way control and for which we bear responsibility. ${ }^{8} \mathrm{~A}$ second feature is the idea that there is no universal answer to the question "How should I live?" Every individual is unique and has to look inward to determine one's own original way of life. In short, authenticity is a framework as well as a moral ideal: "the idea that we each have a way of living that is uniquely our own, and that we are each called to live in our own way rather than that of someone else." 9

According to Elliott an ethic of authenticity is related to the concerns regarding the use of drugs, such as Prozac, for enhancement purposes. First, if meaningful life is linked with authentic life, then there is the possibility of inauthentic life, i.e., a life that is not uniquely and truly yours. Some people feel unease with respect to the use of Prozac in cases of alienation because a personality change seems to be in conflict with an ethic of authenticity: even though Prozac may give you a better personality, it is not your personality. ${ }^{10}$

Secondly, Elliott suggests that there is a strained relationship between a medical approach in these cases and the idea of uniqueness that is included in an ethic of authenticity. Many Americans experience a sense of meaninglessness if they think their lives are not unique.

Finally, Elliott stresses the relationship between an ethic of authenticity and the idea of self-fulfilment. Self-fulfilment is a crucial aspect of a meaningful life. It contains the idea that we have to pursue our values and our talents and that we waste our lives if we fail; it is a higher form of life, a moral ideal. This ideal can be recognized in the ambivalence regarding the use of Prozac: on the one hand, Prozac can be valued as a means to strive for and realize a meaningful and happy life, but on the other hand, the idea of a meaningful life involves authenticity and uniqueness, discovering your own values by looking inward instead of being dependent on an antidepressant. Elliott suggests that the ideal of self-fulfilment may turn out to be oppressive; if you feel unhappy and think you have a meaningless life, you have a duty to change it because you do not want to waste your life. "If Prozac is seen as a kind of ticket to self-fulfilment, and self-fulfilment is your duty, then maybe we can begin to understand why Prozac has become so wildly popular among Americans." 11

It would hardly surprise us if Elliott argued that the psychiatrist should not prescribe Prozac for the man in his example; his concern is that this use would invite inauthenticity. A person may be better off 
being in a predicament and being aware of it than being in a predicament and not being aware of it. As Parens asserts, critics like Elliott do not want to glorify suffering but they do want to show that compromising our awareness is bad: "it threatens to separate us from who we really are and how the world really is." 12

Although Elliott's explanation of our concerns as rooted in the ideal of authenticity seems plausible, his interpretation of authenticity remains rather unprecise. He explicitly states that he does not adhere to the view of the idea of an essentialist self: a self with fixed and essential characteristics, a self with a core identity, but he does not elaborate on this point. In his recent book, Human Identity and Bioethics, DeGrazia explicitly discusses the concerns of Elliott and The President's Council on Bioethics but argues that there are no fundamental identity-related arguments against enhancement technology. ${ }^{13}$ Is he right?

\section{COSMETIC PSYCHOPHARMACOLOGY: A MEANS TO SELF-IMPROVEMENT AND AUTHENTICITY?}

DeGrazia thoroughly analyses the concept of personal identity and applies his theory of human identity to several pressing bioethical issues, such as the authority of advance directives and the moral permissibility of enhancement technologies. ${ }^{14}$ DeGrazia makes use of a distinction between numerical and narrative identity. Numerical identity concerns the question "What makes a person at one time and a person at some other time one and the same person?"15 How can things persist, how can human beings maintain their identity despite major changes physically as well as mentally? According to a psychological approach, we are essentially persons and our identity persists in psychological continuity - a perspective which DeGrazia labels Personalism. Another view holds that we are essentially brains with the functional capacity to support consciousness - this is the embodied mind account.

DeGrazia argues for a biological approach because this would be metaphysically more plausible, coherent, and consistent with "educated common sense." 16 Human persons are essentially human animals, members of the species homo sapiens. The term "essentially" must be noted here. In DeGrazia's theory, essence and existence are linked. That is because the question "What are the criteria for a person to continue to exist over time?" is related to another question 
"What are we human persons most fundamentally or essentially?" The idea that I can survive some transformations implies that there must be criteria for my identity and that "the basic kind that determines those criteria also determines my essence."17 "Essentially" is defined as the conditions of persistence: "If property $\mathrm{X}$ is both necessary and sufficient for the thing's existence, then $\mathrm{X}$ is the essence of that thing."18 According to a biological approach the persistence conditions are those of the human organism: we are essentially human animals. This approach is clearly distinguished from a personalist view: even members of our species who will never attain the status of persons, such as anencephalics who do not possess the capacity for consciousness, belong to the species of human animals.

Numerical identity is a prerequisite, an essential condition for narrative identity. Narrative identity concerns different questions, such as "Who am I?" and "Which characteristics, acts, and values make me the person I am?" Under normal conditions, we are more than human animals: we have self-knowledge and a self-narrative, which makes us capable of planning and decision-making. These capacities are sufficient for moral agency and moral responsibility, but many of us want even more: we want to develop our talents, to shape our personality, to be a certain person, to create ourselves. In short, according to DeGrazia, human persons are: 1) essentially human animals and 2) "characteristically self-narrators and (where circumstances permit) self-creators who care about continuing as such."19

This account of human persons is applied to the issue of enhancement technologies, including cosmetic surgery, cosmetic psychopharmacology, and genetic enhancements. DeGrazia argues that there are no fundamental identity-related arguments against enhancement technologies, such as cosmetic psychopharmacology. There are no identity-related arguments that can justify prohibiting or even discouraging the use of such technologies. According to DeGrazia, critics of enhancement technologies neglect the distinction between numerical and narrative identity; they reason as follows:

1. Enhancement technology E alters a person's identity.

2. Altering a person's identity is highly problematic. Therefore,

3. Enhancement technology $\mathrm{E}$ is highly problematic. ${ }^{20}$

DeGrazia argues that this reasoning is flawed: the first premise can only be true if narrative identity were at stake (because enhancement technology cannot literally destroy a person and replace him with 
another). The second premise can only be assumed if it appeals to numerical identity. Therefore the conclusion cannot be drawn.

\section{THE IMPORTANCE OF IDENTITY}

Although DeGrazia believes this settles concerns regarding identity, however, I do not believe that he succeeds in eliminating the kind of identity-related and authenticity-related concerns of critics like Elliott.

The first reason I think DeGrazia's theory does not succeed in eliminating Elliott's concern has to do with his account of identity. DeGrazia argues that enhancement technologies can only be highly problematic in the case that numerical identity is at stake. Moral status is solely attributed to numerical identity. But what do we really find important about identity?

According to Schechtman, with whom I agree on this point, we attach importance to personality because of four basic features of personal identity. ${ }^{21}$ These four features are: 1) moral responsibility (a person can only be held responsible for his own actions); 2) selfinterested concern ("there is a type of interest one properly has only for oneself"); 3) compensation ("a person can only be compensated for his sacrifices by benefits that accrue to him"); and 4) survival (we are not solely interested in biological continuity but especially in psychological continuity, that one will still be around in the future).

Schechtman argues that psychological continuity theorists-who argue that personal identity should be defined in terms of the continuation of a single psychological life - are unable to explain the importance attached to identity. The reason is that they try to answer the question of personal identity in terms of re-identification: asking whether the consciousness at $\mathrm{t} 2$ is the same consciousness as that at $\mathrm{t} 1$ (which is similar to the question of numerical identity). ${ }^{22}$ It seems that psychological continuity theorists find themselves in a Catch-22 situation: if they manage to develop a logically consistent answer to the re-identification question they will be liable to the extreme claim (that is, they can not account for the importance we attach to identity), while a notion of sameness of consciousness over time that does account for the importance of the four features does not seem to be logically consistent. Instead of rejecting our intuitions and forcing ourselves to argue that persons should be identified by either their body or their psyche, Schechtman suggests an alternative view. There 
are no different answers to one single question, but "distinct answers to different questions." The re-identification question can best be answered by a bodily criterion whereas the characterization question ("which values, desires, views, and other psychological characteristics make someone the person she is?") is most properly answered by a psychologically-based criterion. Both questions can be asked about the same person. We are interested whether the person who is arrested for having committed a crime is really the same person as the one who committed the crime (for example by checking DNA) because we think this is pertinent for determining moral responsibility. Although both questions are related, Schechtman underlines the different perspectives the questions provide on identity.

The re-identification question is an important question of personal identity in certain situations, but only the characterization question is able to account for the importance attached to personal identity. Whereas the re-identification question requires an absolute answer, the answer to this question can be gradual: someone can be more or less responsible, more or less alive. As an example Schechtman quotes a patient of Peter Kramer's: "She had not been alive before taking an antidepressant." 23 We do not need to see this as just a metaphor. Although there is an important difference between a patient who lost consciousness permanently and someone who is being abused and lost her identity, they are all conditions on a continuum: "... the degree to which a person is alive, and hence survives, seems linked to the degree to which her actions, experiences, and characteristics are her own - the degree to which her identity is expressed in her life."24

Stories of radical changes in human lives, whether by means of drugs or other technologies, show how these may affect personal narrative identity in such a way that survival of identity is threatened. For example, the story of a man suffering from obsessive-compulsive disorder; he used medication and had psychotherapy for twenty-two years without any effect. ${ }^{25}$ As a last resort he chose a new treatment called Deep Brain Stimulation: a surgical implantation of a medical device which sends electrical impulses to specific parts of the brain. After the surgical implantation it took one year to adjust the electrodes; every three weeks he had to go to the hospital to find the optimal adjustment that would lessen the symptoms while preventing side-effects. Some adjustments caused a hyper-energetic state: he was tireless, impulsive, and assertive. Other adjustments caused an intensely happy feeling. During this period of adjustment and dramatic changes in character traits he seemed to be a different 
person; friends and family did not recognize him as the person he used to be and he even lost some friends. This shows that changes in narrative identity do matter a lot.

DeGrazia argues that enhancement technologies can only be problematic in cases where numerical identity is at stake. However, numerical identity has very little relationship with the four basic features that we care so deeply about. Narrative identity does; but according to DeGrazia changes in narrative identity are not morally problematic. DeGrazia's account - in which numerical identity is central - is thus not capable of explaining the importance we attach to narrative identity and to changes in this identity. This is one reason why his argument cannot settle the concerns of critics like Elliott.

\section{MORAL CONCERNS REGARDING AUTHENTICITY}

The second reason why DeGrazia, in my view, does not succeed in setting concerns at rest has to do with his account of autonomy and authenticity. DeGrazia argues that one cannot object to enhancement technologies as long as autonomous choices are made and considerations of safety and justice are taken into account. His definition of autonomy subscribes to the view of Gerald Dworkin who analyses autonomy as authenticity which requires higher-order identification with one's first-order desires. This process of identification has to be free of alienating influences. ${ }^{26}$ DeGrazia sharpens the analysis of autonomy as follows: "A autonomously performs intentional action $\mathrm{X}$ if and only if (1) A does $\mathrm{X}$ because she prefers to do X, (2) A has this preference because she (at least dispositionally) identifies with and prefers to have it, and (3) this identification has not resulted primarily from influences that A would, on careful reflection, consider alienating." ${ }^{27}$ Not respecting the autonomous choice of competent adults is morally problematic.

According to DeGrazia, authenticity as a concept, defined as "being true to oneself" and as "presenting oneself to others as one truly is," does not set any additional limits. ${ }^{28}$ Although it is problematic to deceive or cheat others and perhaps ourselves about who we are, authenticity per se does not "add any morally significant concern." ${ }^{29}$ Concerns for problematic uses of enhancement technologies can be understood in terms of respect for autonomy and honesty. Dishonesty is interpreted as systematic deception towards others about who one really is and is characterized as inauthentic. 
As an example, DeGrazia pictures a woman longing to look like a Barbie doll. ${ }^{30}$ She may be socialized by sexist norms; her desire to change her appearance may not be her real desire if she is not aware of these norms and their impact on her desire. In that case, her choice is neither autonomous nor authentic (authentic in the sense of higherorder identification with first-order desires). Our concerns about authenticity and honesty are, in fact, concerns about autonomy. According to DeGrazia, every self-creation project that is autonomous and honest is ipso facto authentic.

Does this account settle the concerns of critics? I do not think so and, moreover, it does not seem to quiet the concerns of DeGrazia himself. First, I believe DeGrazia's notion of authenticity is too narrow. DeGrazia introduces Chiang, a man who is brainwashed and whose mission is to burn books and to torture intellectuals; Chiang is even grateful for the brainwashing. In asking whether we should test the legitimacy of an influence prospectively or retrospectively, DeGrazia argues that a retrospective evaluation would be appropriate: "If Chiang wants to burn books, identifies with his desires, understands the party's influence on him yet embraces this influence - not just publicly but in his heart - then Chiang has genuinely changed and his desire, I suggest, is autonomous, harmonizing as it does with his current worldview." 31

In DeGrazia's account, authenticity is fulfilled as long as critical reflection has taken place and alienating influences are absent. Whether or not influences are alienating, however, seems to depend again on critical reflection. ${ }^{32}$ The emphasis on careful reflection, however, does not capture the reason why we find certain influences on desireformation both alienating and problematic. As Insoo Hyun argues, our reasons for judging someone's values or choices as inauthentic has to do with the circumstances in which his values are enclosed, "what we find objectionable are the actual reasons why the people in such situations possess their particular values." ${ }^{33}$ The people in Huxley's Brave New World are happy and would defend their values if required and may even critically reflect on them, but their choices are not autonomous: their values are not truly their own, and their values are forced upon them by bio- and socio-technological engineering.

As Hyun argues, the authenticity condition requires a broader approach, beyond the concept of critical reflection. Securing authenticity involves more conditions: "the absence of certain external, social constraints." ${ }^{34}$ Concern about inauthentic values is concern about persons being compelled to have the values they in fact 
possess. People can be compelled to accept values in situations where (1) they are "denied access to alternatives that are reasonable and presently available to others who have similar capacities and abilities" and (2) when they are "barred from these other options for reasons that are morally illegitimate." ${ }^{, 35}$ Inauthentic values do not exist solely in circumstances of brainwashing and manipulation but may also occur in situations where reasonable alternatives are absent. What is important is that people live in circumstances where reasonable and legitimate alternatives remain open to them and where they are able to challenge values. This broader notion of authenticity is defined in a negative sense, based on the absence of certain circumstances, and upon a particular premise of the nature of the self, namely people's relational situation: "people come deeply 'embedded' in personal relationships and shared social roles and practices." ${ }^{36} \mathrm{In}$ contrast, interpretations of authenticity in which critical reflection is central seem to be based on a different premise, namely people as selfdetached individuals independently reflecting on their own values.

Second, it seems as if DeGrazia's own concerns are not completely settled by his own account. The example I have in mind here concerns alterations (physically or mentally) that are done for frivolous reasons. "One might agree that accidentally altering one's breasts, or intentionally doing so to improve one's health, is beyond reproach, while holding that intentionally doing so for something as frivolous as cosmetic improvement is indefensible or at least highly problematic." ${ }^{37}$ DeGrazia is concerned about these kind of enhancements, but his own account seems inadequate to explain or justify these concerns. How can DeGrazia evaluate the choice of a woman to change her appearance in order to improve her looks as frivolous and highly problematic as long as her choice is autonomous? DeGrazia speculates that this may have to do with insufficient self-respect. Although he raises the question of whether authenticity and even autonomy require self-respect, he unfortunately does not go deeper into this topic.

This example illustrates that DeGrazia may have some concerns that are not adequately captured by his theoretical account of personal identity and authenticity. Moreover, he seems to need a thicker conception of personal identity, authenticity, and self-fulfilment in order to make sense of his concerns regarding the use of enhancement technology for frivolous reasons. I agree with Erik Parens that even proponents of enhancement technologies have a less formalistic idea of what being an authentic self or a self-fulfilled person is than they are accustomed to acknowledging. ${ }^{38}$ Consider, for 
instance, if a pill could be produced that would engender the perception of intimacy. ${ }^{39}$ According to Parens, even honest proponents would acknowledge that "enhancements" such as these are troubling because giving people the idea of intimacy while genuine intimacy is absent seems to conflict with the moral ideal of authenticity. If people had "intimate" relationships as a result of this pill, they would not be considered to be living authentically.

It is important to recognize that Parens's interpretation of authenticity is different from that of Hyun's and DeGrazia's. Whereas Hyun's interpretation comes down to formulating conditions that distinguish authentic from inauthentic values, Parens uses authenticity as a moral ideal of self-fulfilment (at least in his analysis of the debate). This interpretation is more in line with the views of Elliott discussed earlier. I do agree with Parens and Elliott that enhancement technologies raise questions that can not be answered by retreating to a thin conception of the authentic self. We need a thicker conception of what self-fulfilment and personhood mean. However, this is a dangerous project. History shows how easily thick conceptions of personhood and real happiness can undermine individual freedom and autonomy. In our search for what is essential about ourselves we have to be constantly aware of the question that proponents such as Kramer and DeGrazia ask: "Who sets the values?" ${ }^{40}$ Who determines which circumstances lead to alienation and what self-fulfilment really means? Who determines when a technology severs how one feels from how one lives?

\section{POLICY AND CHALLENGES}

As shown in the preceding section, authenticity can be interpreted in different ways: as a more global conception referring to an ideal of self-fulfilment and "thick" personhood, or as a more narrow conception related to a specific account of autonomy and value formation.

Enhancement technologies confront us with new possibilities to enhance human functions and characteristics. Troubling cases such as the "perceived intimacy" pill demonstrate the need for a debate that includes thick concepts of authentic personal identity, and reflects both on the meaning of self-fulfilment and on what living truly or authentically means. ${ }^{41}$ Authenticity in this broad interpretation, as an ideal of human flourishing, should play a role in the enhancement debate. An important task of a government is therefore to foster and support such a debate. 
Currently, enhancement technologies that go beyond what we understand as the normal or naturally human do not yet exist. However, we need to respond to the question of how to deal with a variety of psychopharmacological substances that are already being used, in the grey area between medical treatment and human enhancement. Should they be provided by physicians under certain conditions? Or should they be regulated outside of the medical realm, in a commercial setting? Synofzik has introduced a moral framework for a medicine-on-demand which is built on the traditional principles of beneficence, non-maleficence and autonomy. ${ }^{42}$ He proposes a continuum between a physician's firm recommendations of an intervention at one end, to a refusal to intervene at the other end. In between, physician and patient should deliberate on the risks and benefits in the light of a patient's own autonomous preferences. The risk-benefit analysis of the physician has to be based on general values instead of on his own subjective values. Interesting issues here concern the degree to which a physician can question the patient's values, preferences (and their authenticity), or can impose society's values on the client. If we choose DeGrazia's interpretation of authenticity this would imply that a physician should carry out requests that are based on the clients' self-confessed values and preferences. A somewhat broader interpretation of authenticity, such as Hyun's, requires a physician to do more than carry out the client's requests - the physician can also question the authenticity of the client's values; for example, the social influences at work during their formation. Providing psychopharmacological substances for enhancement purposes in a medical setting gives a better opportunity to deliberate with the client and to explore her motives than would a commercial setting. Consider, for instance, Elliott's example of the accountant "living in Downers Grove, Illinois who comes to himself one day and says, 'Jesus Christ, is this it? A Snapper lawn mower and a house in the suburbs?",43 Although I do not want to overstate the possibilities of physicians to determine whether a person's values are authentic or not, to a certain extent it must be possible to explore whether a client's values and choices are manipulated or undermined and, as Hyun puts it, to inquire whether that person is able to challenge her values and to see whether reasonable alternatives have been foreclosed. This interpretation of authenticity demands more of physicians than taking a client's values and choices as simply given. 


\section{ACKNOWLEDGEMENTS}

I would like to thank two (anonymous) reviewers from Theoretical Medicine and Bioethics who contributed greatly to the improvement of this paper. Special thanks are due to Maartje Schermer for her helpful and detailed comments on earlier drafts of this paper. The research for this paper was supported by a grant from the Netherlands Organisation for Scientific Research (NWO).

\section{NOTES}

1 M.J. Farah, J. Illes, R. Cook-Degan et al., "Neurocognitive enhancement: what can we do and what should we do?" Nature Reviews Neuroscience 5, no. 5 (2004): $421-25$.

2 J.A. Caldwell Jr., J.L. Caldwell, N.K. Smythe, "A double-blind, placebo-controlled investigation of the efficacy of modafinil for sustaining the alertness and performance of aviators: a helicopter simulator study," Psychopharmacology (Berl) 150 (2000): 272-82; M.J. Mehlman, "Cognition-Enhancing Drugs," The Milbank Quarterly 82, no. 3 (2004): 483-506.

3 J.A. Yesavage, M.S. Mumenthaler, J.L. Taylor, "Donepezil and flight simulator performance: effects on retention of complex skills," Neurology 59 (2002): 123-25; G. Grön, M. Kirstein, A. Thielscher et al., "Cholinergic enhancement of episodic memory in healthy young adults," Psychopharmacology (Berl) 182 (2005): 170-79.

4 E. Parens, "Authenticity and Ambivalence: Toward Understanding the Enhancement Debate," The Hastings Center Report 35, no. 3 (2005): 34-41.

5 C. Elliott, "The Tyranny of Happiness: Ethics and Cosmetic Psychopharmacology," In Enhancing Human Traits: Ethical and Social Implications, ed. E. Parens (Washington D.C.: Georgetown University Press, 1998), p. 178.

6 Elliott, cited in n. 5, above, p. 180.

7 The President's Council on Bioethics, Beyond Therapy. Biotechnology and the Pursuit of Happiness, New York: DANA Press, 2003.

8 Elliott, cited in n. 5, above, p. 181.

9 C. Elliott, Better than Well. American Medicine Meets the American Dream (New York: W.W. Norton \& Company, 2003), pp. 28.

10 Elliott points out how words such as "authenticity" are being used to express concern and unease (threaten our true selves) but also to justify the use of enhancers: "It is a way of justifying them to yourself, countering the imagined criticism that they represent a kind of phoniness, narcissism, or status-seeking" (Elliott, 2003, p. 38).

11 Elliott, cited in n. 5, above, p. 187.

12 Parens, cited in n. 4, above, p. 36.

13 D. DeGrazia, Human Identity and Bioethics (New York: Cambridge University Press, 2005).

14 DeGrazia uses the term "human identity" instead of "personal identity" because the latter term seems to suggest a personal definition. 
15 DeGrazia, cited in n. 13, above, p. 13.

16 Ibid., p. 47.

7 Ibid., p. 28.

8 Ibid., p. 29.

19 Ibid., p. 114.

20 Ibid., p. 232.

21 M. Schechtman, The Constitution of Selves (New York: Cornell University Press, 1996).

22 Schechtman, cited in n. 21, above, p. 136.

23 Ibid., p. 88 .

24 Ibid., p. 89.

25 R.Tammer, "Genezen van een dwangneurose," Psychologie Magazine June (2006): 22-25.

26 G. Dworkin, The Theory and Practice of Autonomy (Cambridge: Cambridge University Press, 1988).

27 DeGrazia, cited in n. 13, above, p. 102.

28 Ibid., p. 108.

29 Ibid., p. 110.

30 Ibid., p. 112.

31 Ibid., p. 102.

32 See DeGrazia's definition of autonomy: "this identification has not resulted primarily from influences that A would, on careful reflection, consider alienating" (emphasis added).

33 I. Hyun, "Authentic Values and Individual Autonomy," The Journal of Value Inquiry 35 (2001): 202.

34 Ibid., p. 201.

35 Ibid., p. 204.

36 I. Hyun, "Waiver of Informed Consent, Cultural Sensitivity, and the Problem of Unjust Families and Traditions," The Hastings Center Report 32, no.5 (2002): 16.

37 DeGrazia, cited in n. 13, above, p. 234.

38 Parens, cited in n. 4, above, p. 37.

39 Ibid., p. 39.

40 P. Kramer, "The Valorization of Sadness: Alienation and the Melancholic Temperament," The Hastings Center Report 30, no. 2 (2000).

41 Parens, cited in n. 4, above.

42 M. Synofzik, "Kognition à la carte? Der wunsch nach kognitionsverbessernden Psychopharmaka in der Medizin," Ethik in der Medizin 18 (2006): 37-50.

43 Elliott, cited in n. 5, above, p. 180.

\section{REFERENCES}

Caldwell, J.A. Jr., J.L. Caldwell, and N.K. Smythe. "A double-blind, placebo-controlled investigation of the efficacy of modafinil for sustaining the alertness and performance of aviators: a helicopter simulator study." Psychopharmacology (Berl) 150 (2000): 272-82. 
DeGrazia, D. Human Identity and Bioethics. New York: Cambridge University Press, 2005.

Dworkin, G. The Theory and Practice of Autonomy. Cambridge: Cambridge University Press, 1988.

Elliott, C. "The Tyranny of Happiness: Ethics and Cosmetic Psychopharmacology." In Enhancing Human Traits: Ethical and Social Implications. Edited by E. Parens. 177-88. Washington, D.C: Georgetown University Press, 1998.

Elliott, C. Better than Well. American Medicine Meets the American Dream. New York: W.W. Norton \& Company, 2003.

Farah, M.J., J. Illes, R. Cook-Degan, et al. "Neurocognitive enhancement: what can we do and what should we do?" Nature Reviews Neuroscience 5, no. 5 (2004): $421-25$.

Grön, G., M. Kirstein, A. Thielscher, et al. "Cholinergic enhancement of episodic memory in healthy young adults." Psychopharmacology (Berl) 182 (2005): 170-79.

Hyun, I. "Authentic Values and Individual Autonomy." The Journal of Value Inquiry 35 (2001): 195-208.

Hyun, I. "Waiver of Informed Consent, Cultural Sensitivity, and the Problem of Unjust Families and Traditions." The Hastings Center Report 32, no. 5 (2002): $14-22$.

Kramer, P. "The Valorization of Sadness: Alienation and the Melancholic Temperament." The Hastings Center Report 30, no. 2 (2000): 13-18.

Mehlman, M.J. "Cognition-Enhancing Drugs." The Milbank Quarterly 82, no. 3 (2004): 483-506.

Parens, E. "Authenticity and Ambivalence. Toward Understanding the Enhancement Debate." The Hastings Center Report 35, no. 3 (2005): 34-41.

Schechtman, M. The Constitution of Selves. New York: Cornell University Press, 1996.

The President's Council on Bioethics. Beyond Therapy. Biotechnology and the Pursuit of Happiness. New York: DANA Press, 2003.

Synofzik, M. "Kognition à la carte? Der wunsch nach kognitionsverbessernden Psychopharmaka in der Medizin." Ethik in der Medizin 18 (2006): 37-50.

Yesavage, J.A., M.S. Mumenthaler, J.L. Taylor, et al. "Donepezil and flight simulator performance: effects on retention of complex skills." Neurology 59 (2002): $123-5$.

Ethics Institute, Utrecht University, PO Box 801033508

TC Utrecht, The Netherlands

E-mail: l.l.e.bolt@uu.nl

and

Department of Medical Ethics and Philosophy of Medicine, Erasmus MC, Rotterdam, The Netherlands 